Division of Geological \& Geophysical Surveys

RAW-DATA FILE 2007-3

\title{
OUTCROP SAMPLE RESULTS FROM MERCURY INJECTION CAPILLARY PRESSURE ANALYSES, BRISTOL BAY, ALASKA PENINSULA
}

by

Andrea M. Loveland, Rocky R. Reifenstuhl, Robert J. Gillis, and Paul L. Decker

$\$ 2.00$

September 2007

THIS REPORT HAS NOT BEEN REVIEWED FOR TECHNICAL CONTENT OR FOR CONFORMITY TO THE EDITORIAL STANDARDS OF DGGS

Released by

STATE OF ALASKA DEPARTMENT OF NATURAL RESOURCES

Division of Geological \& Geophysical Surveys 3354 College Road

Fairbanks, Alaska 99709-3707 


\section{OUTCROP SAMPLE RESULTS FROM MERCURY INJECTION CAPILLARY PRESSURE ANALYSES, BRISTOL BAY, ALASKA PENINSULA}

By Andrea M. Loveland (andrea.loveland@alaska.gov), Rocky R. Reifenstuhl, Robert J. Gillis, and Paul L. Decker

List of figures

Figure 1 Location map of the study area and MICP sample distribution

Figure 2 Stratigraphic column of the Bristol Bay basin and Alaska Peninsula

Figure 3 Chart of seal capacity in gas/water system

Figure 4 Chart of seal capacity in oil/water system

Figure 5 Chart of potential seal capacity at $7.5 \%$ gas saturation

Figure 6 Chart of potential seal capacity at $7.5 \%$ oil saturation

Table 1 Summary of pore system and capillary properties

Table 2 MICP sample data

Table 3 Summary of height at $7.5 \%$ saturation

\section{Introduction}

This non-interpretive report summarizes the results of mercury injection capillary pressure (MICP) analyses performed on 21 outcrop samples collected from 17 locations during the 2005 and 2006 field seasons from the Port Moller and Herendeen Bay areas of the Alaska Peninsula Bristol Bay basin region, Alaska (fig. 1). Helicopter-supported fieldwork conducted in 2006 by geologists from the Alaska Division of Geological \& Geophysical Surveys (ADGGS) and the Alaska Division of Oil \& Gas (ADOG) marked the end of a three-year geological research project that was funded by the U.S.

Department of Energy through the Arctic Energy Technology Development Laboratory at the University of Alaska Fairbanks, the Bristol Bay Native Corporation, ADGGS, and ADOG. The overall goal of the project was to better understand the hydrocarbon potential of the Bristol Bay basin.

Preliminary mercury injection capillary pressures from five samples were reported previously in Loveland-Strauch et al. (2006), as those were the only results available at the time of publication. Results for those samples are also included in this report. It is important to note that the table showing gas/water and oil/water seal capacity and the associated charts for three samples in that report, contained an error. The error is corrected in this report. 


\section{Mercury Injection Capillary Pressure}

The results of mercury injection capillary pressure (MICP) analyses for 21 outcrop samples from 17 locations in the Staniukovich, Tolstoi, Stepovak, and Bear Lake Formations (fig. 2) are presented in this report. Analyses were performed by PetroTech Associates, Houston, Texas.

Potential seal capacity data for the gas/water and oil/water systems are summarized in Figures 3 and 4, respectively. Figures 5 and 6 illustrate the seal capacity potential at $7.5 \%$ saturation in the seal. The pore system and capillary properties are shown in Table 1. Tables 2 and 3 summarize composite height data.

Figures 3-6 and tables 1-3 are modified from their report to DGGS.

The geographic coordinates and metadata for sample locations in this report are recorded in Loveland-Strauch et al. (2006), but are not included here.

The authors would like to thank Paige R. Delaney (DGGS) for reviewing this report.

\section{References}

Burk, C.A., 1965, Geology of the Alaska Peninsula-Island Arc and Continental Margin: The Geological Society of America Memoir 99, 250 p., 3 sheets.

Decker, P.L., Finzel, E.S., Ridgway, K.D., Reifenstuhl, R.R., and Blodgett, R.B., 2005, Preliminary summary of the 2005 field season: Port Moller, Herendeen Bay, and Dillingham areas, Bristol Bay Basin, Alaska Peninsula: Alaska Division of Geological \& Geophysical Surveys Preliminary Interpretive Report 2005-7, 55 p.

Finzel, E.S., Reifenstuhl, R.R., Decker, P.L., and Ridgway, K.D., 2005, Sedimentology, stratigraphy, and hydrocarbon reservoir-source rock potential, using surface and subsurface data, of Tertiary and Mesozoic strata, Bristol Bay Basin and Alaska Peninsula: Alaska Division of Geological \& Geophysical Surveys Preliminary Interpretive Report 2005-4, 67 p.

Loveland-Strauch, A., Gillis, R., Reifenstuhl, R.R., and Decker, P.L., 2006, 2006 Bristol Bay, Alaska Peninsula field summary and outcrop sample results from porosity and permeability and mercury capillary pressure analyses: Alaska Division of Geological \& Geophysical Surveys Raw-Data File 2006-1, 67 p. 


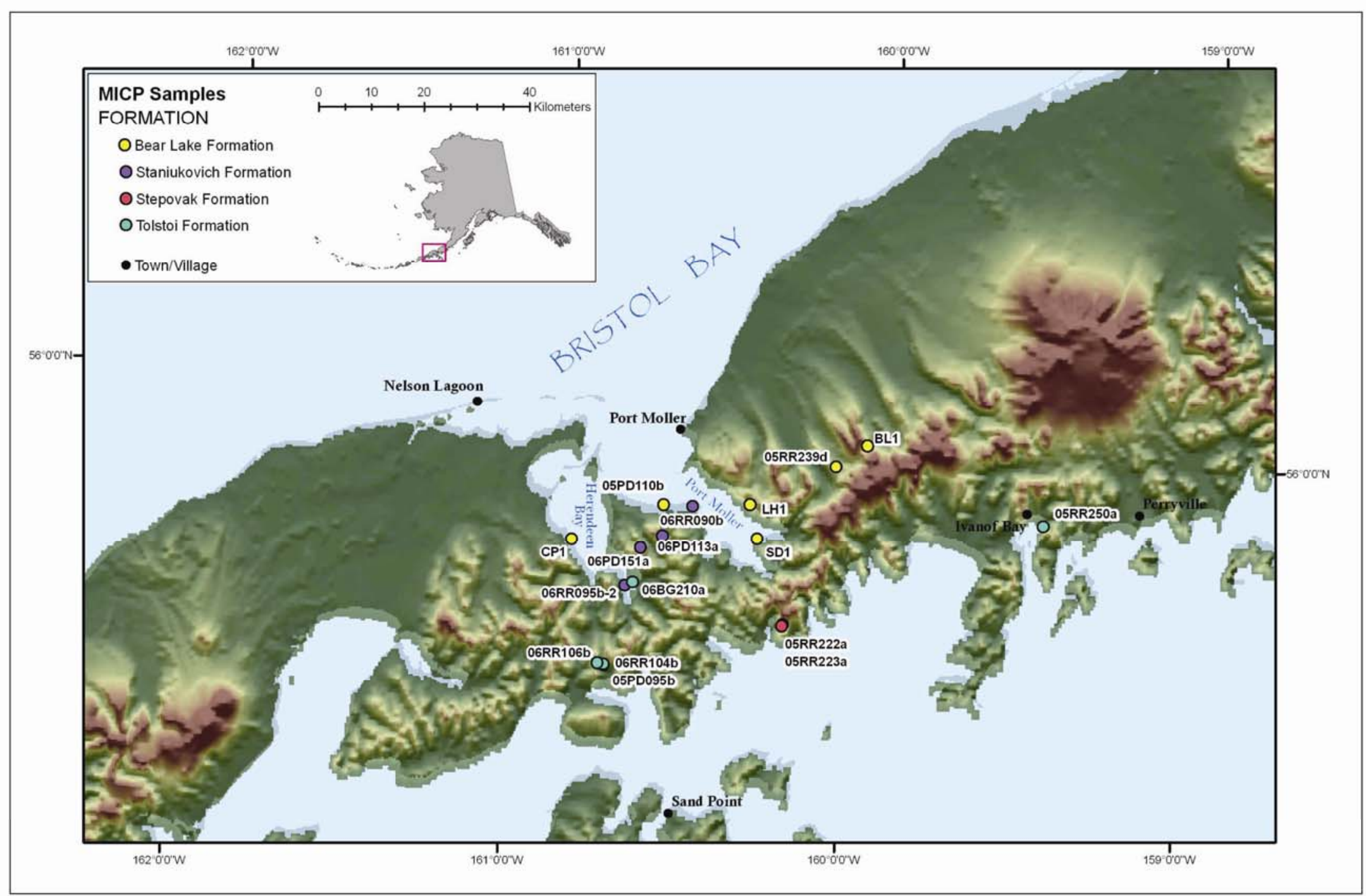




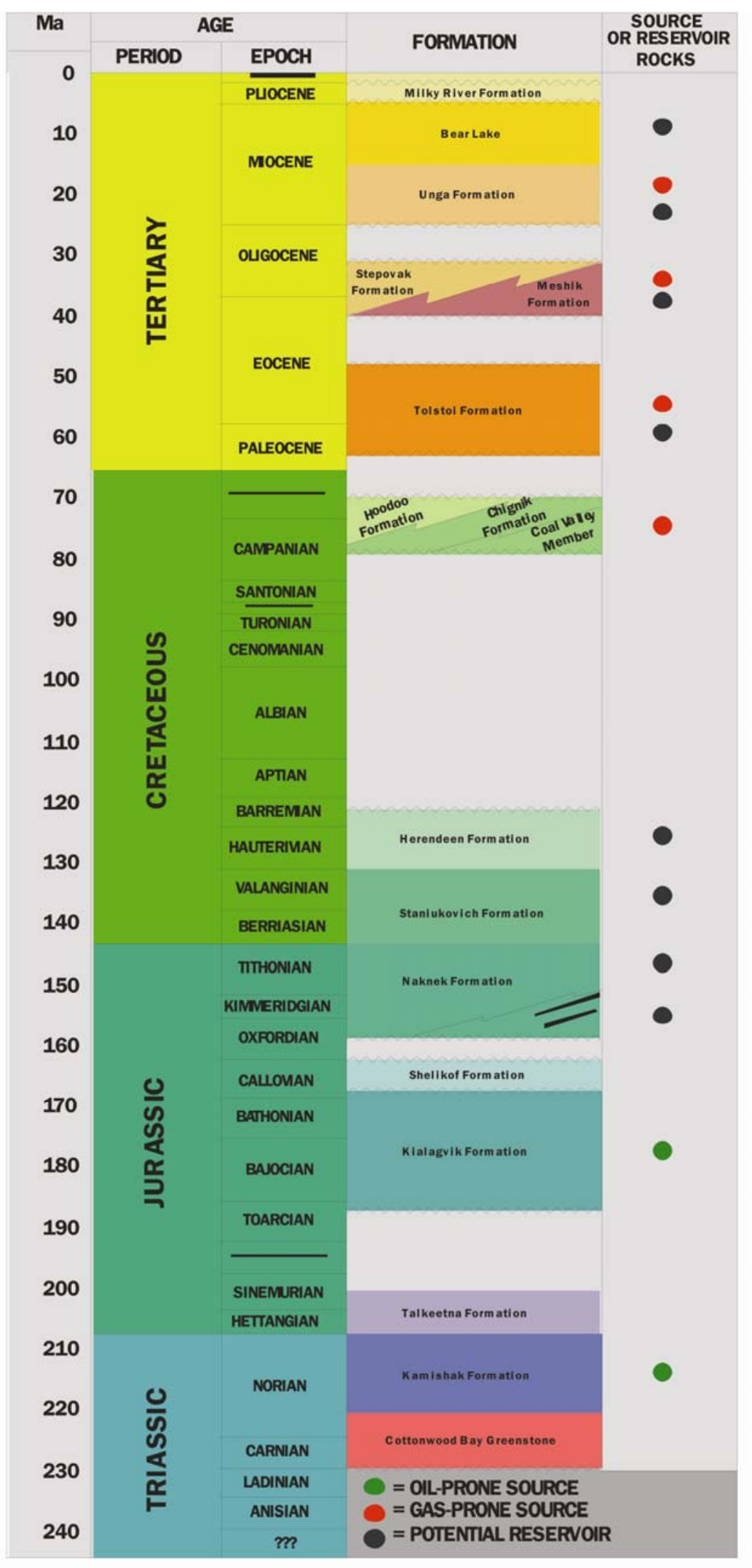

Figure 2. Stratigraphic column of the Bristol Bay area indicating potential source and reservoir units (modified from Burk, 1965). 


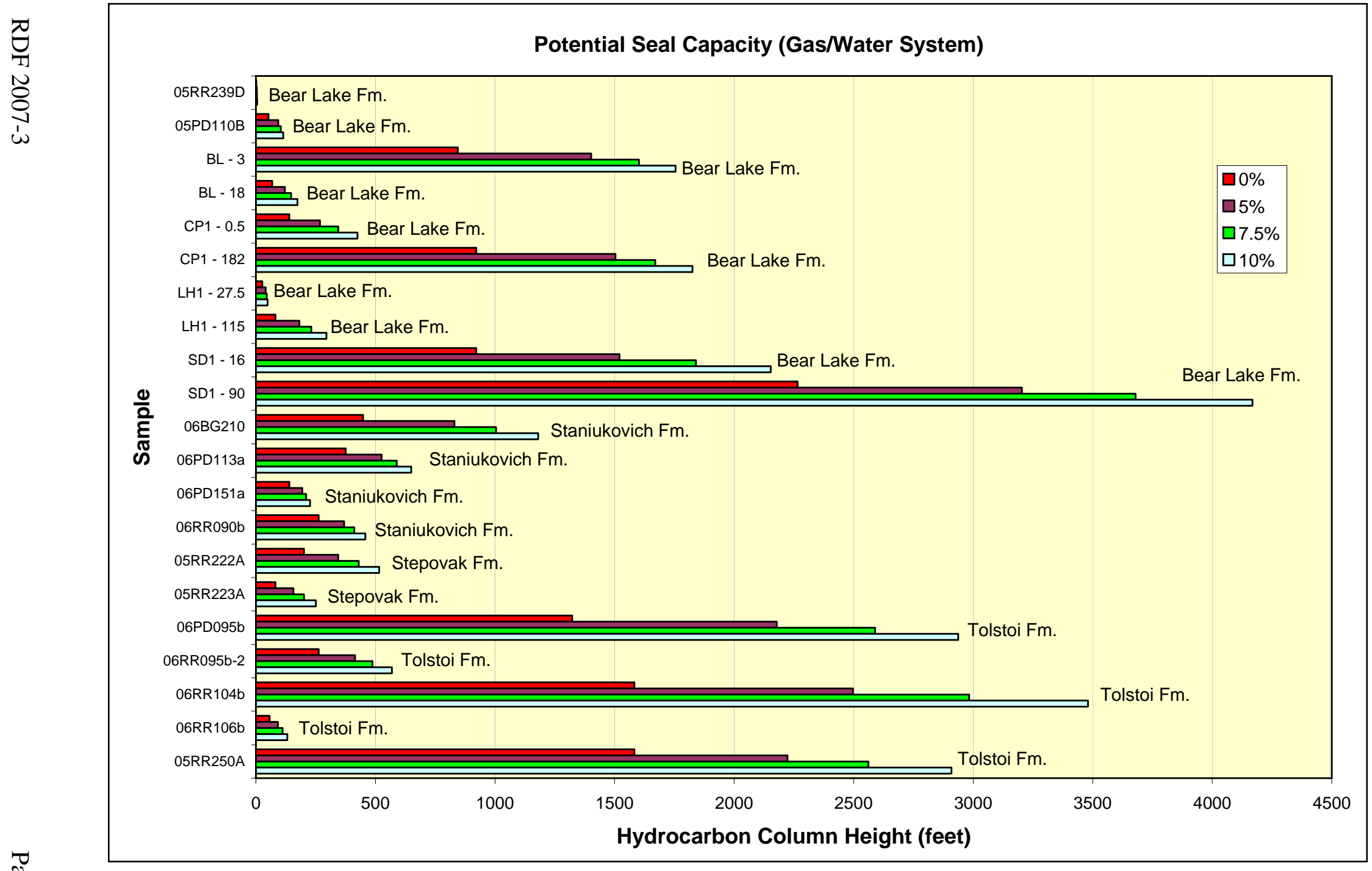

Figure 3. Summary bar graph of potential seal capacity in a gas/water system. 


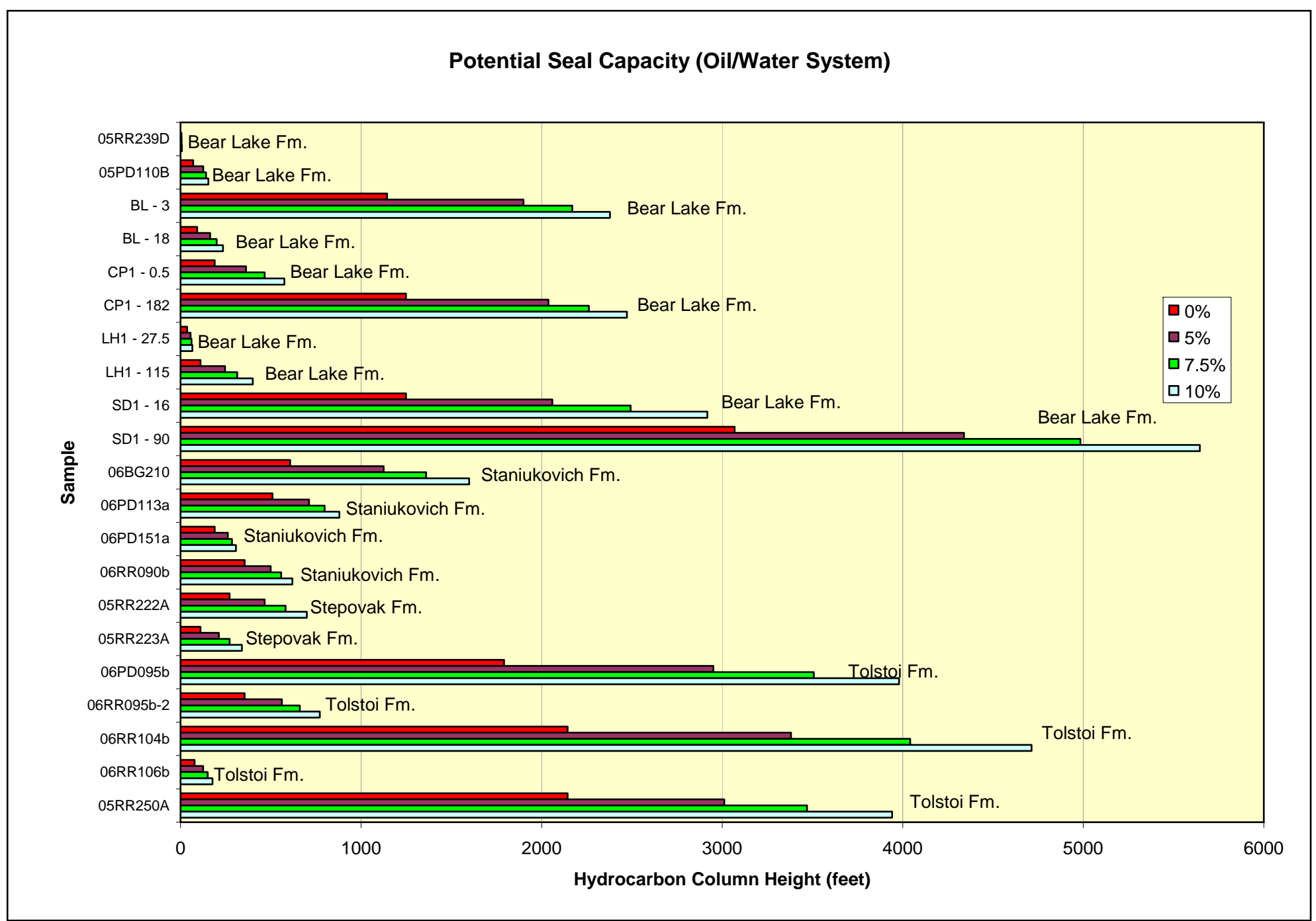

Figure 4. Summary graph of the potential seal capacity in an oil/water system. 


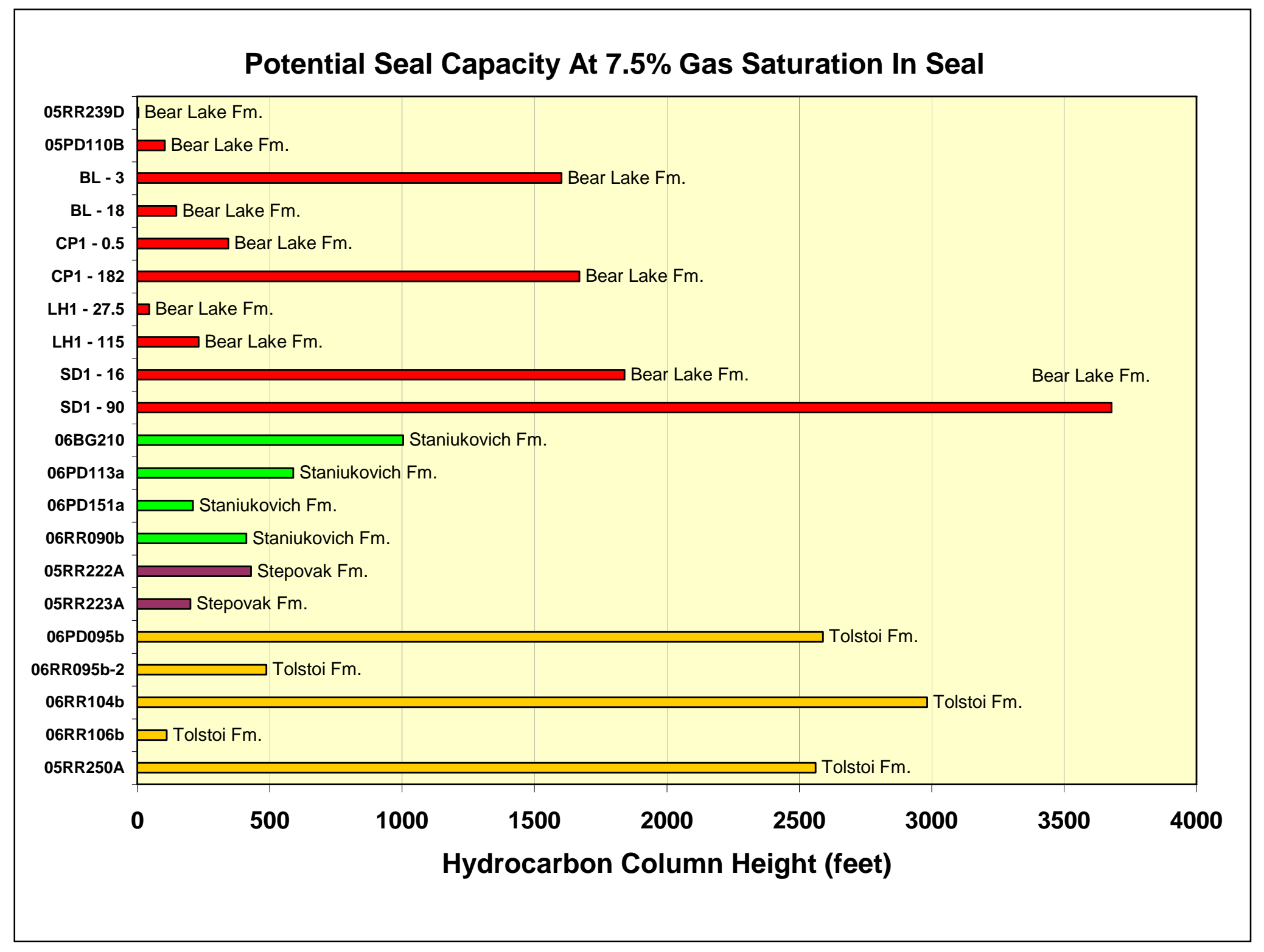

Figure 5. Graph of the potential seal capacity at 7.5\% gas saturation. 


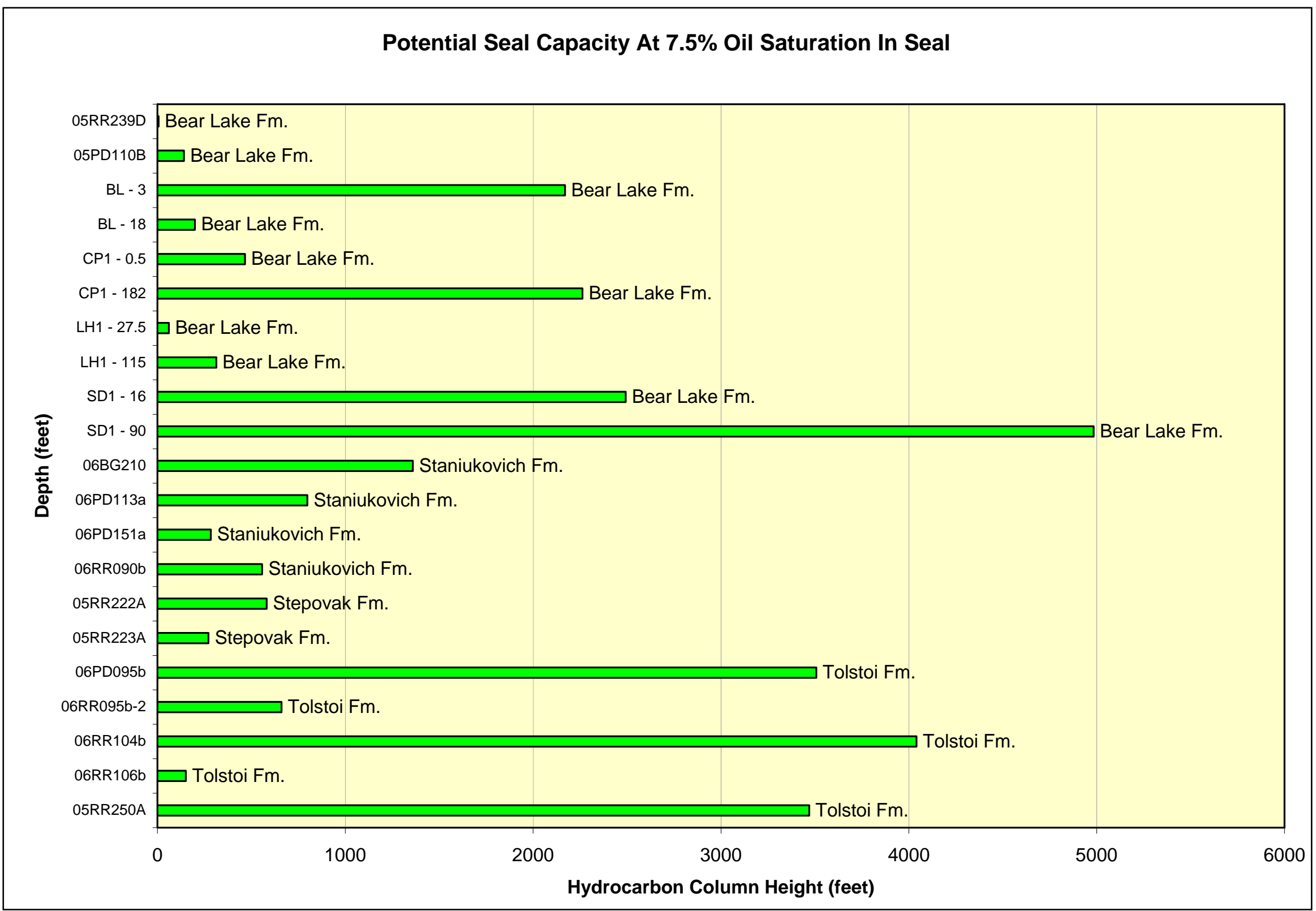

Figure 6. Bar graph summarizing the potential seal capacity at $7.5 \%$ oil saturation. 
Table 1. Pore system and capillary properties summary.

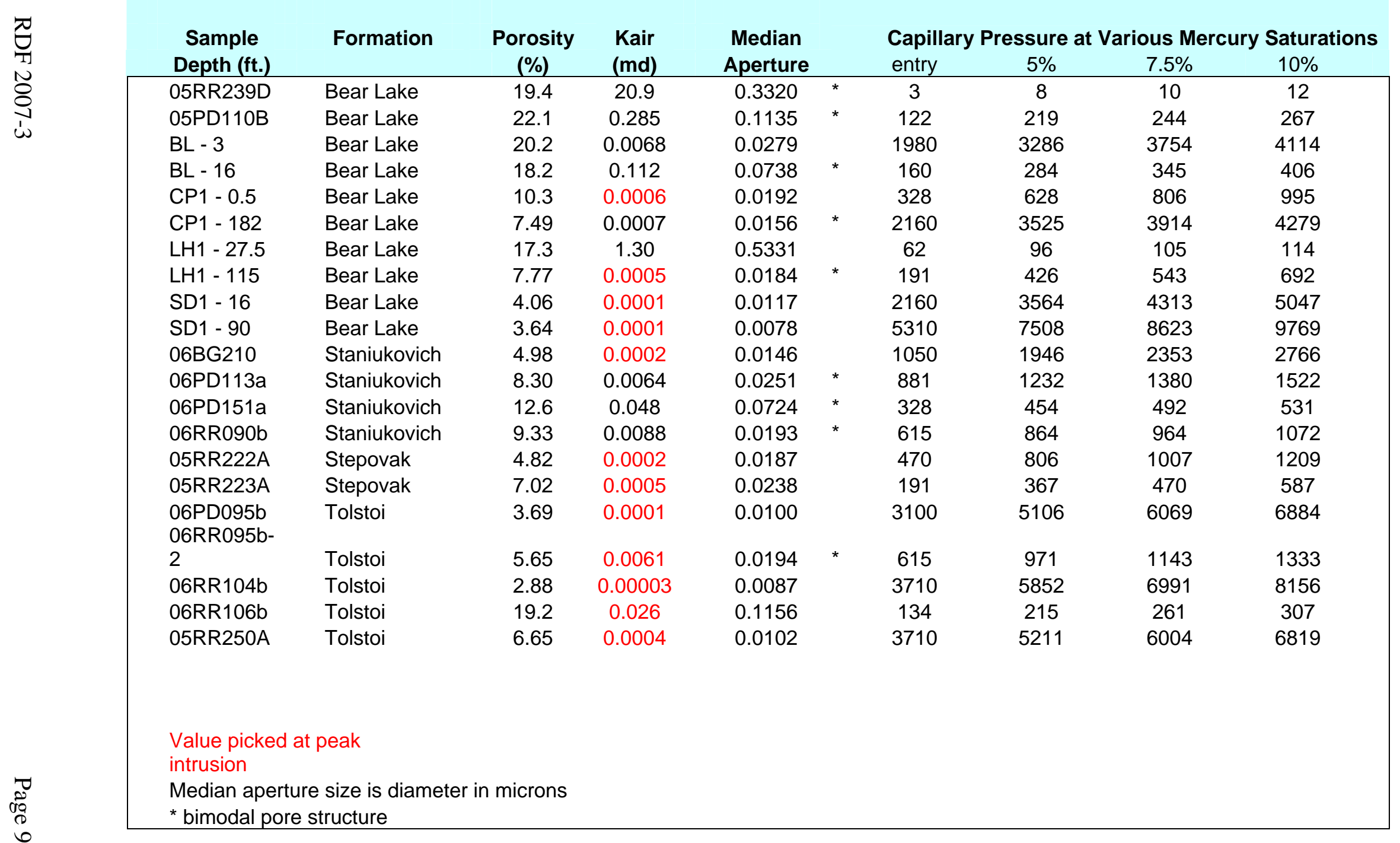


Table 2. Outcrop sample MICP data from the Bristol Bay area.

Outcrop Samples - Composite Height Data

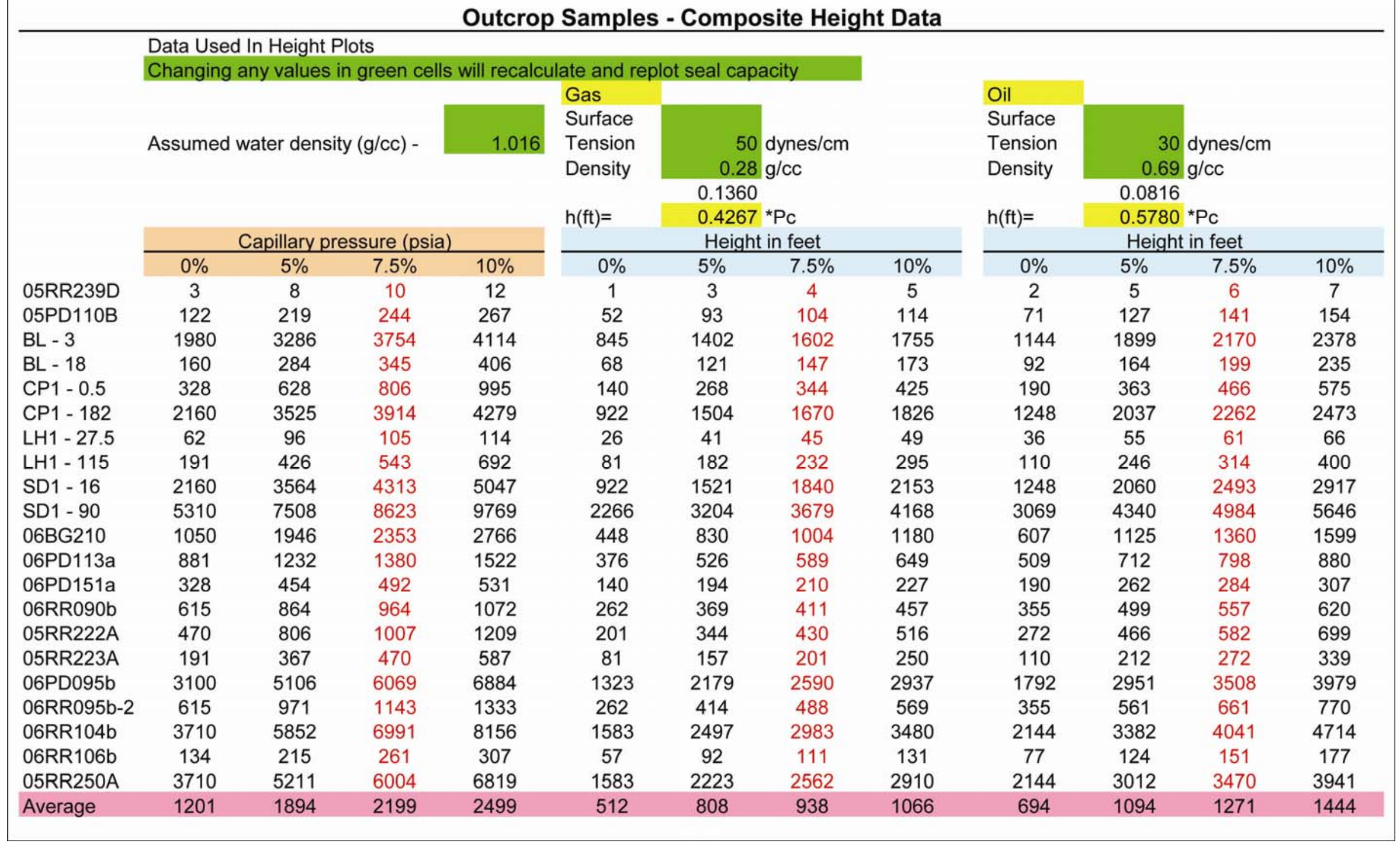


Table 3. Summary of height at 7.5\% saturation.

\begin{tabular}{|lccc|}
\hline \multicolumn{4}{|c|}{ Height @ 7.5\% Saturation } \\
\hline \multicolumn{4}{c|}{ Capillary } \\
Pressure & Gas & Oil \\
05RR239D & 10 & 4 & 6 \\
05PD110B & 244 & 104 & 141 \\
BL - 3 & 3754 & 1602 & 2170 \\
BL - 18 & 345 & 147 & 199 \\
CP1 - 0.5 & 806 & 344 & 466 \\
CP1 - 182 & 3914 & 1670 & 2262 \\
LH1 - 27.5 & 105 & 45 & 61 \\
LH1 - 115 & 543 & 232 & 314 \\
SD1 - 16 & 4313 & 1840 & 2493 \\
SD1 - 90 & 8623 & 3679 & 4984 \\
06BG210 & 2353 & 1004 & 1360 \\
06PD113a & 1380 & 589 & 798 \\
06PD151a & 492 & 210 & 284 \\
06RR090b & 964 & 411 & 557 \\
05RR222A & 1007 & 430 & 582 \\
05RR223A & 470 & 201 & 272 \\
06PD095b & 6069 & 2590 & 3508 \\
06RR095b-2 & 1143 & 488 & 661 \\
06RR104b & 6991 & 2983 & 4041 \\
06RR106b & 261 & 111 & 151 \\
05RR250A & 6004 & 2562 & 3470 \\
\hline
\end{tabular}

